\title{
Toward a spatial-temporal measure of land-use mix
}

\author{
Steven R. Gehrke \\ Portland State University \\ sgehrke@pdx.edu
}

\author{
Kelly J. Clifton \\ Portland State University \\ kclifton@pdx.edu
}

\begin{abstract}
Urban planning and public-health research has long been interested in the connection between land-use mix and travel. Interest from urban planners stems from the potential of transportation efficiency gains achieved by an increased land-use mix and subsequent shortening of trip lengths; whereas, public-health research advocates an increased land-use mix as an effective policy for facilitating greater physical activity. Yet, despite the transportation, land-use, and health benefits related to improving land-use mix and the extent of topical attention given by researchers, no consensus has been reached regarding the magnitude of its effect on travel. This absence of agreement may largely be attributed to the theoretical and methodological failings persistent in present attempts to accurately reflect land-use interaction and operationalize its quantification within a defined spatial extent. To better evaluate the impact of land-use mix on travel behavior and assess more temporal policies, a robust mix measure accounting for these two elements of land-use interaction and geographic scale as well as a temporal element of land-use mixing-missing from present specifications-must be introduced. This paper establishes the research agenda for a spatial-temporal land-use mix measure by (1) identifying the conceptual and methodological faults inherent to current land-use interaction and geographic-scale representations and (2) describing strategies and practical benefits of representing the temporal availability of landuse mixing in guiding innovative transportation/land-use policies.
\end{abstract}

\section{Article history:}

Received: January 9, 2014

Accepted: September 24, 2014

Available online: July 1, 2015

\section{Introduction}

Urban policies encouraging active travel behavior, reducing auto dependence, and mitigating peakhour travel are often rooted in growth management strategies promoting improved efficiencies of the built environment. Plans informed by these policies have envisioned mixed-use neighborhoods with an assortment of residential options surrounded by diverse out-of-home activity destinations. This smart growth strategy maximizes the ability of the built environment to offer residents quick and efficient travel connections. Consequently, an improvement in local accessibility to employment, retail, and recreational opportunities for residents of these compact, mixed-use neighborhoods has been a subject of rewarding examination for urban-planning researchers studying the travel behavior outcomes associ-

Copyright 2015 Steven R. Gehrke \& Kelly J. Clifton

http://dx.doi.org/10.5198/jtlu.2015.725

ISSN: 1938-7849 | Licensed under the Creative Commons Attribution - Noncommercial License 3.0

The Journal of Transport and Land Use is the official journal of the World Society for Transport and Land Use (WSTLUR) and is published and sponsored by the University of Minnesota Center for Transportation Studies. This paper is also published with sponsorship from WSTLUR and the Institutes of Transportation Studies at University of California, Davis and University of California, Berkeley. 
ated with smart growth policies.

Study of the linkages between travel behavior and the built environment have been of particular interest to transportation (Handy et al. 2002) and land-use planners, who have long supported myriad benefits associated with providing a mixture of land-use types at a neighborhood scale (Reilly and Landis 2003). To transportation planners, an increase in the mixing of land uses within an urban neighborhood holds promise as a lever that policymakers may pull to increase active travel mode shares and lower nonwork vehicle miles traveled (Hong, Shen, and Zhang 2013). To land-use planners, the provision of a mix of activity opportunities guides many growth management policies seeking to achieve compact urban development, revitalize aging neighborhoods, and reduce rural land consumption (Downs 2005).

In accordance, urban planning researchers have established numerous land-use mix metrics to investigate the effectiveness of mixed-use policies to achieve their anticipated transportation outcomes. Such metrics have been widely accepted within the formal processes of transportation/land-use planning (Zhang and Kukadia 2005). When employed by urban planners, these land-use mix metrics have sought to both examine the degree to which land-use mixing can encourage active travel (Manaugh and Kreider 2013) and identify the extent of urban sprawl (Zhang and Kukadia 2005). Findings from this line of research have adopted mix metrics to support the continued calls for decision makers to direct land-development efforts that increase the diversity of land-use types in existing neighborhoods (Rodriguez et al. 2009).

Land-use mix and travel-behavior research, traditionally an urban planning interest, has more recently received greater topical attention from the public-health field. To public-health researchers and practitioners, integration of different land uses within a neighborhood reflects an enhancement to the pedestrian orientation of the given neighborhood and improved feasibility and attractiveness for active travel by reducing physical and psychological barriers (Handy et al. 2002). The promotion of policies aimed at improving the viability and appeal of walking and bicycling holds potential as a cost-effective approach for increasing physical activity, limiting the adverse impacts of transportation-related pollution, and fostering the development of neighborhood sense of place (Manaugh and Kreider 2013). As such, a focus on the impact of environmental determinants (e.g., land-use mixing) on physical activity in public-health research has helped inform policy and programmatic recommendations related to the creation of active communities and mitigation of prevalent chronic disease risk factors (Duncan et al. 2010).

An impetus behind the resulting policies is that the built environment—not only individual factors- has an effect on whether or not individuals partake in higher levels of physical activity, which in turn has public health-related implications vis-à-vis obesity, blood pressure, and mental health (Forsyth et al. 2008). Public concerns over rising obesity prevalence and the related adverse impacts of chronic diseases associated with low physical activity levels have directed public-health research and initiatives to consider land-use policies as population health-promotion strategies (Brownson et al. 2009). In response, recent research has refined guidelines centered on the promotion of increased local land-use mixing as an urban policy intervention beholding of long-lasting public health benefits (Frank et al. 2005).

Despite the transportation, land-use, and health-related benefits and extent of topical attention given by researchers, no consensus has been reached regarding the magnitude of land-use mixing's effect on travel and no clear indication of the optimal land-use mix needed to yield its exemplified benefits has been acknowledged. As with general debates of the built environment and travel behavior relationship, a true understanding into the potential impact of land-use mixing on travel has often been predicated on data limitations and methodological variations (Badoe and Miller 2000). Indeed, measurement inconsistencies have hindered any agreement; however, the ability of researchers to advance this area of study must also be founded on a strengthened conceptual basis of how the various elements of land-use 
mix are reflected. Explicitly, a greater focus must be given to three interrelated elements of land-use mix:

- Land-use interaction: quantification of complementary activities represented by land-use types

- Geographic scale: spatial boundary selected to operationalize land-use interaction

- Temporal availability: opportunity to access land-use types within or across time periods

Recognizing the need for additional research, this paper sets the table for future studies to include a land-use mix measure that also considers the temporal availability of land uses. To accomplish this stated goal, our paper details strategies for representing each element and highlights some theoretical and statistical limitations inherent to these past approaches. The previously unexplored temporal availability element is then introduced and discussed as a requisite advancement toward providing policy and practice with an improved understanding of the ways in which land-use mixing impacts travel.

\section{Land-use interaction}

At the center of any built environment depiction is a choice of measurement, where the selected measure must reflect a clear construct of the built environment feature being conveyed and quantified. In defining land-use mix, Handy et al. (2002) described the land-use mix construct as the relative proximity of different land uses within a given area. Ewing and Cervero (2010) defined diversity of the built environment, or land-use mix, as the number of unique land-use types in an area and the relative size of each land-use type. This depiction has differed from the definition provided by Saelens, Sallis, and Frank (2003), which offered a more nuanced description of land-use mix that defined the measure as the level of integration among different land-use types in an area. While seemingly trivial differences, the first depiction defines a distance-based accessibility measure of land-use mix, whereas, the second definition suggests a measure of intensity or pattern in heterogeneous land-use types. Conversely, the last account more accurately reflects the mix construct by suggesting that a land-use mix metric should quantify the functional complementarity of diverse land-use types. The spatial integration of synergistic land uses is likely to produce the travel outcomes desired by smart growth policy advocates favoring mixed-use developments as a strategy for improving the viability of active transportation options (Handy 2005).

\subsection{Measuring land-use interaction}

In reviewing studies on the association between the built environment and transport, Brownson et al. (2009) adopted a classification scheme proposed by Song and Rodriguez (2005) segmenting land-use mix measures into three categories: accessibility, intensity, and pattern. Although the described typology has likely embodied an imperfect sorting of all mix measures, the distinction of three measurement types will provide a structure for unraveling the complicated nature of quantifying land-use mix. A related acknowledgement of an unsettled boundary for classifying various built environment measures has been noted elsewhere (Ewing and Cervero 2010).

While often not explicitly regarded by transportation researchers as a land-use mix measure, the concept of accessibility has often been quantified as a distance-based measure capturing the spatial proximity of separate activity locations. Distance-based accessibility measures have arisen from defining accessibility as the ease of individuals to reach an urban opportunity from a given activity location (Kwan and Weber 2008). At the foundation of this interpretation has been the definition put forward by Hansen (1959) in which the notion of intensity was detached from prior accessibility measures in favor of a stricter version only pertaining to the potential of opportunity interaction. Convention to parse 
intensity from accessibility supports the identification of accessibility and intensity as unique strategies for measuring mix. Geurs and van Wee (2004) stated that a comprehensive accessibility measure must possess the four interrelated components of land use, transport, time, and the individual. The distribution of various activities (land uses) may inform travel demand and introduce temporal constraints affecting the availability of urban opportunities to an individual. Advancing this logic, an increase in the mixing of land uses represents the potential for shortening trip lengths and improved ability to conduct activities.

A second category of land-use interaction measures has quantified the intensity of a land-use type in an area-described as a count or percent. A count-based land-use mix measure may be quantified by tallying the number of opportunities related to a land-use type within an area (Brownson et al. 2009). Remaining intensity measures have been quantified as a percentage of land in a defined area dedicated to a particular land-use type (Song, Merlin, and Rodriquez 2013). As with count-based mix measures, percent-based spatial measures may easily be computed to offer practical information related to the intensity of a land use in an area. If a land-use type under examination is relatively scarce, a percentbased measure alone can yield meaningful results (Song, Merlin, and Rodriguez 2013). In contrast, the choice of a count-based metric for linking a recreational land use (e.g., park) to an active travel outcome likely underestimates the relative importance of that land use in an area, which may be more suitably quantified as a percent-based measure accounting for the spatial expanse of a recreational land use. Consequently, the land-use type under investigation should inform the selection of an appropriate intensity measure (Song and Rodriguez 2005).

Pattern measures quantifying the spatial composition and configuration of land-use types within an area represent the final category of interaction measures. The spatial pattern identified as the variety of land-use types within an area (composition) and the proximity of those land uses to one another (configuration) has been recognized as an important set of ecological measures in travel research (Clifton et al. 2008). Pattern measures have alternatively been labeled as divisional measures - sensitive to subtle land-use patterns in an area — and integral measures—only sensitive to the overall distribution of landuse types in a defined area (Song, Merlin, and Rodriguez 2013). In the literature, entropy-based (Frank and Pivo 1994) and Herfindahl-Hirschman (Forsyth et al. 2008) indices reflect two common integral measures, whereas, the dissimilarity index (Cervero and Kockelman 1997) reflects a common divisional measure. Despite being commonplace, many pattern, accessibility and intensity measures of land-use interaction suffer from a set of conceptual and methodological limitations.

\subsection{Concerns with measuring land-use interaction}

Present land-use interaction measures often remain imperfect conceptual and methodological realizations of land-use mixing adopted from ecology research and economic theory (Clifton et al. 2008). Case in point, entropy measures are often plagued by a central assumption that an even balance in the land uses of an area is representative of an ideal condition (Manaugh and Kreider 2013). Many travel-behavior studies have adopted this atheoretical notion of equal distribution and subsequently produced measures of heterogeneity rather than complementarity (Hess, Moudon, and Logsdon 2001). A neighborhood with an evenness in residential, office, and retail opportunities likely generates some transportation efficiencies; however, the substitution of the residential land use for industry likely produces a completely different set of travel outcomes despite having an identical entropy measurement. Given the lack of agreement on what types and proportion of land uses to include in a mix measure, it is unsurprising that previous studies have found an increased mix to have a negligible (Duncan et al. 2010) or counterintuitive effect (e.g., Bhat and Gossen 2004) on travel.

Methodological inconsistencies and concerns also exist with present land-use mix measures. Often, 
analyses into the connection between land-use mix and travel behavior have been conducted at the triplevel and separated work from nonwork travel. If we consider the described neighborhood with residential, office, and retail land uses, there exists the possibility of an individual residing in that neighborhood to perform an activity at the retail establishment upon leaving his/her workplace for home. The ability to capture the travel benefit related to this land-use interaction may only be achieved by adopting a strategy linking mix to tour-level travel behaviors (Hanson 1980; Krizek 2003a).

Many percent-based measures are also unable to capture the finer travel implications of having smaller intermittent parcels in a neighborhood because these mix measures typically sum the disaggregate parcels into a single statistic representing the percent of a land use in an area. Composition or integral measures are arguably the more common type of pattern measure; however, these measures are unable to account for any reversing of the land-use type proportions (Manaugh and Kreider 2013) and are insensitive to any further division of the parcels (Song, Merlin, and Rodriguez 2013). In contrast, prior configuration or divisional measures often have shortcomings related to an: inability to be compared with mix at a regional scale, insensitivity to the arrangement of adjacent areas (Frank and Pivo 1994), and dependence on the scale chosen to operationalize the pattern measure (Song, Merlin, and Rodriguez 2013). Finally, researchers must be cognizant of the inconsistencies that exist across datasets regarding how disaggregate parcels were summarized into general land-use categories or how variable construction differed in past studies. Thus, future measures of land-use interaction must be validated to promote transferability and an accurate translation of empirical findings into policy initiatives.

\section{Geographic scale}

Explicit consideration must be given to the concept of scale, because of its pervasiveness in all measures of space and time (Hess, Moudon, and Logsdon 2001). Unfortunately, past research quantifying the neighborhood effect of land-use mix has provided insufficient attention to the intrinsic bond between land-use interaction and geographic-scale selection when measuring the mix construct. A consequence has been an investigation into the effect of mix on travel utilizing a wide variety of geographic scales (Mitra and Buliung 2012). Without greater empirical insight, the choice of geographic scale will remain a perplexing complication confounding an accurate assessment of the association between travel and accessibility, intensity, and pattern measures of land-use mix (Kwan and Weber 2008).

\subsection{Operationalizing land-use interaction}

Operationalization of a land-use interaction measure at a selected geographic scale has generally been determined by analytical convenience or restrictions in data availability, prohibiting a richer understanding of the scale at which land-use mixing most affects travel. In urban planning and public health literature, various strategies have been used to delineate a physical landscape and characterize the built environment found within its boundary. These strategies for geographic-scale definition may be classified as the adoption of a fixed, sliding, or perceptive scale.

The choice of a geographic scale based on a predefined set of non-overlapping boundaries represents the application of a fixed geographic scale to operationalize land-use mix. Fixed geographic scales reflect the measurement of land-use mix within a discrete boundary that may be nested into a hierarchical spatial representation (Guo and Bhat 2007). This attractive characteristic of fixed zonal schemes may permit a more comprehensive analysis of how the influence of mix on travel differs across a set of nested spatial extents (Kwan and Weber 2008).

A common adoption of a fixed geographic scale has been the depiction of the built environment within an administrative boundary. Measuring land-use mix at a fixed geographic scale delineated by 
a community- or government-based entity to achieve specific organizational objectives has exemplified the use of an administrative boundary. While no theoretical support has linked the adoption of this scale for travel-behavior research, decisions to use an administrative scale have often been supported by an anticipated availability of socio-demographic, housing, and other land-use characteristics also found at this scale (Kwan and Weber 2008) since these territories are usually characterized by an explicit set of rules dictating their geographic delineation (Gauvin et al. 2007). Use of a statistical boundary to operationalize land-use mix has been a second fixed geographic scale ubiquitous in travel-behavior research. A statistical boundary like a census geography is usually smaller in area than an administrative boundary, which has bolstered their adoption. Operationalizing mix at a census geography has other benefits underscoring its attractiveness, including the ease of obtaining socio-demographic data at a coinciding scale (Guo and Bhat 2007) and the attempt of these fixed scale boundaries to objectively approximate neighborhood design (Manaugh and Kreider 2013). The creation of an artificial boundary has represented a final category of fixed geographic scale choice. Generation of a uniformed, synthetic zoning system (e.g., Krizek 2003b) to assess the neighborhood effect of mix has represented the adoption of this category of fixed scales.

In contrast, the choice of a sliding geographic scale has embodied an attempt to more accurately explain those built environment features that matter most to travel behavior by placing an individual at the center of his or her surrounding built environment (Guo and Bhat 2007). Beyond the individualcentric depiction of scale that allows for overlying geographic boundaries, a sliding scale delineation has also offered a conceptual advancement to its fixed scale counterpart by allowing individual variation in neighborhood definition. Methodologically, by measuring mix at a sliding geographic scale, past studies have removed some statistical bias introduced by analyzing the effect of the built environment for an individual located at the perimeter, rather than center, of a fixed geographic scale (Oliver, Schuurman, and Hall 2007).

Past sliding scale applications have varied on whether or not to incorporate the street network or an unconstrained straight-line distance, or use one or multiple activity locations to operationalize a measure. Per the former decision, past studies have operationalized a built environment measure such as land-use mix by using circular buffers that extend from a specific central location (e.g., residence) without an account of artificial or natural barriers in the surrounding environment (Mitra and Buliung 2012; Clark and Scott 2014). Other studies have accounted for these physical constraints faced by an individual in his or her surrounding environment by confining the areal buffer to only include an area accessible by use of the surrounding street network (Frank et al. 2008; Christian et al. 2011). Each sliding scale technique has typically measured the mix of land uses around one activity location; however, the decision to account for multiple activity locations, demonstrated in the creation of an activity space, has led to the development of a final class of sliding geographic scale. The concept of an activity space, which originated in the field of time geography, has reflected an attempt to recognize the actual and potential engagement of an individual in an activity provided at a given land use (Fan and Khattak 2008). Hence, the delineation of an activity space has defined the spatial area in which the movements of an individual are confined (Lenntorp 1976), which restricts any neighborhood effect to only include the environment actually used by an individual (Miller 2005). As such, use of an activity space to measure the relationship between land-use mix and travel behavior may represent individual-based restrictions outside street network impedance.

Beyond an objective measurement of land-use mix represented by an individual's activity space, there exists a subjective quality of the built environment related to an individual's perception of what may be physically reached or factors in his or her decision for activity engagement (Horton and Reynolds 1971). The subjective utility of the built environment may be objectively captured by the creation 
of a perceptive geographic scale in the form of a mental or cognitive map. In his seminal work into this topic, Lynch (1960) described these perceptive scales as being the generalized picture of the exterior physical world held by an individual comprised of countless paths, edges, districts, nodes, and landmarks. Provided with this understanding, the ability to objectively define any built environment feature at a perceptive scale has represented a challenging endeavor to travel-behavior researchers since mental maps dynamically change over time based on the built environment qualities observed by an individual during the execution of an activity or trip (Arentze and Timmermans 2005).

\subsection{Concerns with operationalizing land-use interaction}

In part due to the countless strategies for operationalizing the built environment, no agreement has been reached regarding the choice of an optimal scale to estimate the impact of land-use mix on travel (Duncan et al. 2010). Given the natural bond between measurement and scale in which parameter estimates depend on the zonal scheme choice (Kwan and Weber 2008), greater attention must be given toward how land-use mix is measured for different travel modes and trip purposes. While some research has examined the impact of measuring mix at different scales on mode choice (Zhang and Kukadia 2005; Mitra and Buliung 2012; Gehrke and Clifton 2014), this limited evidence base must be bolstered to clearly understand what scales are most suitable for the travel mode or trip purpose in question. For instance, an individual deciding whether to walk or bike may be influenced by different land uses since the latter mode may enable access to more activities in the same travel time. Similarly, the travel time budget of an individual conducting a discretionary trip may be larger than that of an individual commuting; leading to the former individual being potentially influenced by a wider set of land uses within a larger activity space. Hence, land-use interaction must be operationalized at multiple geographic scales that conceptually correspond with the research context (Clark and Scott 2014).

While the use of sliding scales to operationalize land-use mix reflects a conceptual advancement to fixed scale applications, the strategy remains an objective approach to measuring the neighborhood effects of the built environment without sensitivity to the individual perceptions of the surrounding environment. Future travel studies should examine the theoretical benefit of operationalizing land-use interaction at a perceptive scale by testing the use of mental maps (Arentze and Timmermans 2005). Methodologically, sliding scale applications have tended to use distance as the sole impedance factor informing their calculation; however, future studies should account for other constraints such as travel time, physical effort, and traffic safety. In the end, variety in network distance selection and lack of reported procedural descriptions for computing some sliding scales has restricted the transferability of these scales to other contexts (Brownson et al. 2009), leaving researchers little justification for selecting either scale to analyze the impact of land-use mix on travel (Kwan and Weber 2008).

The modifiable areal unit problem (MAUP) represents an established methodological concern affecting the choice to utilize a fixed or sliding geographic scale to analyze the land-use mix and travel connection. Fotheringham and Wong (1991) described the MAUP as being the sensitivity of analytical results to the definition of a geographic scale at which any spatial data are collected. Evaluating the impact of the MAUP on travel behavior may be divided into scale and zoning effects. The level of aggregation used to measure the built environment has defined the former effect, while the configuration of a geographic scale system has defined the latter (Fotheringham and Wong 1991). Variations in scale size have resulted in a scale effect on analytical results (Mitra and Buliung 2012) in which inconsistent findings are attributed to the operationalization of land-use mix at different scales for the same travel outcome (Hong, Shen, and Zhang 2013). Additionally, alterations to the geographic scale that built environment data were originally collected, which is considered the basic spatial unit for measuring the spatial phenomena, have produced inconsistent results related to the representation of mix with an un- 
intended zonal arrangement (Mitra and Buliung 2012). Despite the long-standing recognition of these effects in the geography literature, the MAUP has received less attention in research examining the built environment and travel relationship.

\section{$4 \quad$ Temporal availability}

Time is a fundamental concept to the study of the transportation/land-use connection since an individual's ability to access and participate in an activity at a given location is shaped by the temporal availability of that opportunity (Kwan 2013). Since travel demand derives from the requirement of an individual to partake in an out-of-home activity, any variation in the surrounding land-use supply (e.g., temporal availability) will to some extent impact an individual's revealed travel behavior (McNally and Kulkarni 1997). Accordingly, the failure to account for the temporal availability of a land use (e.g., facility opening hours), a proxy for activity opportunity supply (Yoon and Goulias 2010), has embodied a clear conceptual and methodological omission of past measures created to estimate the neighborhood effect of land-use mixing on travel decisions.

A proposal to include the temporal availability element in future land-use mix measures draws heavily from the study of time geography. An adoption of concepts introduced by this geography subfield, which has informed recent activity-based travel demand modeling approaches, has provided an adaptable framework for a systematic description of the spatial-temporal nature of behavioral constraints faced by an individual (Burns 1979). Behavioral restrictions characteristic of this time geography strategy for understanding activity participation have been summarized as the capability, coupling, and authority constraints faced by a traveler (Hagerstrand 1970). In this framework, the consideration of the temporal availability of an activity or land use represents a potential authority constraint to the behavior exhibited by a traveler, who cannot feasibly access a temporally unavailable opportunity. In thinking about shopping activity participation, an individual may only feasibly conduct this activity during the opening hours of the shopping establishment (Neutens et al. 2007). Extending this illustration to a land-use mix metric, a land use serving as a proxy for this shopping activity would also only influence travel behavior if temporally available to the individual; therefore, a temporally unavailable land use should likewise not be considered in a metric evaluating the impact of land-use mixing on travel behavior.

Travel-related interest in an explicit representation of the temporal element has stemmed from the desire for more time-sensitive dynamic network assignment (Chiu et al. 2011). Further interest has arisen from a growing interest in activity-based approaches to examine the scheduling and execution of activities over time. In response, great advancement in the collection of detailed information to understand the demand for activities over time and space has been achieved; however, commensurate supply-side information detailing the temporal availability of land uses has thus far trailed. An ability to identify the temporal availability of land uses would provide an accurate depiction of activity engagement potential, improve the specification of feasible destination choice sets, and allow for the assessment of temporally sensitive transportation/land-use policies.

\subsection{Representing temporal availability}

Recalling the typology of land-use interaction measures, temporal availability has only been studied in measures of accessibility. Explicit attention to the temporal availability of an activity location to an individual traveler in an accessibility measure has the potential to provide a higher-quality time-space representation of the feasible opportunities available to an individual traveler and, therefore, benefit the predictions of his or her travel behavior (Chen et al. 2011). Traditionally, access to an activity location has been treated as a static temporal assumption with minimal acknowledgment to the diurnal vari- 
ability of service provisions (Neutens et al. 2012). However, the persistent application of accessibility measures with this static time assumption has marginalized the reality that these activity locations have specific temporal schedules or opening hours rendering them unavailable to a traveler at certain hours of the day (Kwan 2013). In response, three strategies for representing the temporal availability of activities within an accessibility measure have been recently explored.

The most direct strategy for representing temporal availability has been to collect and incorporate data pertaining to the opening hours of an establishment. However, the collection of high-quality temporal availability data has remained costly and time consuming (Kwan 2013); thus, hindering the adoption of this strategy. Applying a constraint-based approach to analyzing joint trip making, Neutens et al. (2007) proposed the creation of a spatial-temporal accessibility measure in which the analysis concentrated on the facilities in which opening hours were identified. The temporal availability of these facilities may then be aggregated into any time interval to establish the area of an individual's activity landscape for a specified time period (Neutens et al. 2012).

A second strategy for reflecting temporal availability in a spatial-temporal accessibility measure has been to fix an assumed opening hour schedule on all facilities. In the assumed temporal availability strategy, all facilities or those providing a similar service are assigned identical opening hours (Neutens, Schwanen, and Witlox 2011). In exploring the effect of geographic-scale variability on individual accessibility, Kwan and Weber (2008) utilized a spatial-temporal accessibility measure based on the assumption of a prior study (Weber and Kwan 2002) that all commercial and industrial opportunities were only temporally available from 6 a.m. to 9 p.m. In the latter study, an accessibility measure sensitive to temporal availability displayed significant variation across several fixed geographic scales.

Finally, recent research has presented a strategy for measuring temporal availability acknowledging the difficulty of collecting existing opening hour data as well as the shortcomings of an assumed temporal availability strategy for measuring accessibility. Chen et al. (2011) introduced an activity-related strategy in which the revealed activity arrival and departure times of an individual were used to assign a weighted percent of reachable workers per time interval for various establishments. In this activityrelated strategy, a certain business type has been considered temporally available to an individual traveler if any employee for that specific industry was observed to be performing a work-related activity during that time period.

While the inclusion of an authority constraint reflecting the temporal availability of an activity has received minimal attention in accessibility-related measures (Miller 1999), this mix element has received virtually no consideration when specifying intensity or pattern mix measures. The integration of temporal availability into measures of these other land-use interaction categories may enable an analysis of mixing at either the site level or neighborhood level (Figure 1). The former distinction of temporal availability centers on a little-understood notion that land-use mixing may occur within a single building (Kockelman 1997) or space and that some land-use types in a building may exhibit a synergistic relationship across different time periods. 


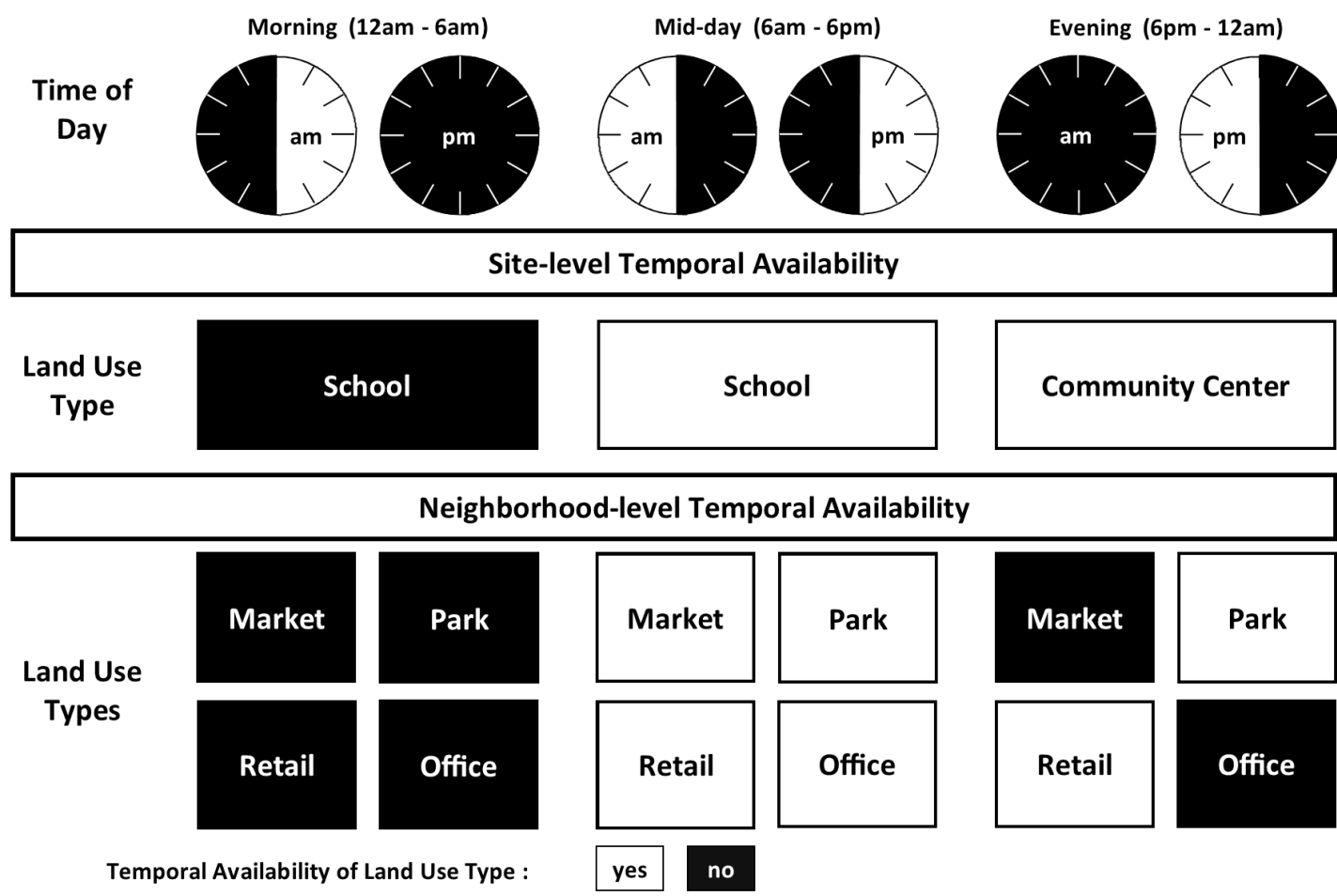

Figure 1: Illustration of the possible temporal availability of land uses in an exemplar neighborhood across three time intervals in a single day

The latter distinction of land-use mixing that occurs at a neighborhood level represents a more widely understood distinction in which certain land uses found in close proximity may exhibit a synergistic relationship within the same time period. This representation of land-use mix reflects the established ideal of smart growth supporters in which certain land uses (e.g., residence, market) may be integrated more harmoniously than other blends if the intention is to induce active travel outcomes. Current intensity and pattern measures inflate the neighborhood level of land-use mixing by not accounting for the temporal availability of activity locations. For instance, a grocery store located in close proximity to an individual's residence may not be accessible to that individual if his or her out-of-home activity schedule excludes them from accessing the market during its opening hours (Kwan 2013).

\subsection{Benefits of representing temporal availability}

Beyond its clear conceptual contribution, the incorporation of temporal availability in future land-use mix measures may be translated into practical benefits related to the support of transportation/land-use policies, identification of social inequities in spatial-temporal accessibility, and improvement of travel demand behavior modeling. Built environment measures representing temporal availability have direct implications on transportation policies impacting local communities (Neutens, Schwanen, and Witlox 2011). Portland Metro has proposed an activity level hierarchy (14-hour, 18-hour, and 24-hour) for select neighborhoods based on residential population, business activity, the built environment, and transportation options (Metro 2011); however, the activity spectrum has not been supported by any empirical-based measure with sensitivity to temporal availability. A measure sensitive to the temporal availability of land uses may help direct active travel initiatives seeking to bring functional origin and destination pairings closer to one another. Relatedly, an identification of the precise blend of land-use 
types needed for an efficient spatial-temporal distribution of activity locations informed by a spatialtemporal mix measure may help guide infill or new development projects and more precisely model the travel implications.

An adoption of a spatial-temporal measure also holds potential toward informing the management of businesses considering an extension of opening and closing hours (Yoon, Ravulaparthy, and Goulias 2014). The liberalization of opening hours may enable individuals to conduct activities outside standard business hours; subsequently, providing individuals with an ability to combine out-of-home activities and improve their prospects for trip chaining (Neutens, Schwanen, and Witlox 2011). Also, an inclusion of the temporal availability element in future mix measures will improve the instruction of sharedparking arrangements in which a parking structure used by the employees of an office building during the day may be used in the evening by drivers accessing entertainment opportunities (Cervero 1996). For each application, research is needed to enhance the capability of temporally sensitive measures to inform transportation planning and practice (Neutens, Schwanen, and Witlox 2011).

Another exciting prospect from the standpoint of travel-behavior research is the consideration of the spatial-temporal accessibility inequities faced by individuals who rely on active travel modes (Neutens et al. 2012). An account of the temporal availability of urban opportunities offers significant insight into the ways that certain individuals or market segments may be affected by variations in the opening hours of facilities found in a neighborhood (Weber and Kwan 2002). Thus, the creation of a mix metric accounting for temporal availability has an ability to evaluate how different opening hour configurations for certain types of services may benefit or hinder those individual disparities in accessing basic human services (Delafontaine et al. 2011). Without consideration for temporal constraints such as opening hours, conventional mix measures have remained insensitive to fluctuations in the availability of certain activities over the course of a day or week. A consequence of this mismatch between the need for activity engagement and temporal availability of the activity may be social exclusion (Neutens, Schwanen, and Witlox 2011).

Finally, specification of a mix measure incorporating an authority constraint will improve activitybased travel demand models, which have to-date largely concentrated on the coupling constraint of individuals within a household interacting with one another (Yoon and Goulias 2010). By disregarding the temporal availability of certain activities or land uses, present models may underestimate the demand for conducting certain activities and in turn distort future travel demand patterns by poorly allocating where activities may occur in the future (Kwan 2013). For that reason and others, the representation of spatial-temporal travel decisions and the built environment factors influencing activity participation must be better understood within future activity-based travel research (Yoon, Ravulaparthy, and Goulias 2014). The creation of a comprehensive land-use mix measure accounting for the temporal availability of specific land-use types helps to fulfill this request.

\section{Conclusion}

Future land-use mix measures must improve how the land-use interaction and geographic-scale elements of the land-use mix construct are represented, while introducing the temporal availability element. Figure 2 synthesizes the strategies for representing each element of a spatial-temporal land-use mix measure and rates the methodological complexity of adopting each strategy. This paper has identified each element and discussed some conceptual and methodological concerns hampering the three interrelated elements of a spatial-temporal land-use mix measure. As detailed disaggregate data and improved technologies become increasingly available to researchers, the importance to advance constructs related to each of these mix elements will become ever more important to understanding the true association between land-use mixing and travel behavior. Urban-planning and public-health researchers interested 
in the adoption of land-use mix policies must continue to challenge the adoption of flawed measures to provide decision makers with a more astute assessment of how increased local land-use mixing relates to travel.

\begin{tabular}{|c|c|c|c|}
\hline $\begin{array}{l}\text { Land Use Mix } \\
\text { Element }\end{array}$ & \multicolumn{3}{|c|}{$\begin{array}{l}\text { Methodological Approach } \\
\text { (less complex } \rightarrow \quad \text { more complex) }\end{array}$} \\
\hline \multirow{2}{*}{$\begin{array}{c}\text { Land Use } \\
\text { Interaction }\end{array}$} & Accessibility & Intensity & Pattern \\
\hline & * Distance-based & $\begin{array}{l}\text { * Count-based } \\
\text { * Percent-based }\end{array}$ & $\begin{array}{ll}* & \text { Composition } \\
* & \text { Configuration }\end{array}$ \\
\hline \multirow{2}{*}{$\begin{array}{l}\text { Geographic } \\
\text { Scale }\end{array}$} & Fixed & Sliding & Perceptive \\
\hline & $\begin{array}{l}\text { * Administrative } \\
\text { * Statistical } \\
\text { * Artificial }\end{array}$ & $\begin{array}{l}\text { * Areal Buffer } \\
\text { * Network Band } \\
\text { * Activity Space }\end{array}$ & * Mental Map \\
\hline \multirow{2}{*}{$\begin{array}{c}\text { Temporal } \\
\text { Availability }\end{array}$} & Known & Assumed & Activity-related \\
\hline & $\begin{array}{l}\text { Stated opening } \\
\text { hours at which an } \\
\text { activity location } \\
\text { may be accessed }\end{array}$ & $\begin{array}{l}\text { Fixed assignment } \\
\text { of opening hours } \\
\text { for all locations of } \\
\text { a similar regime }\end{array}$ & $\begin{array}{l}\text { Imputed assignment } \\
\text { of opening hours } \\
\text { based on revealed } \\
\text { activity participation }\end{array}$ \\
\hline
\end{tabular}

Figure 2: Summary of methodological approaches for representing the three elements of land-use mix

\section{References}

Arentze, T., and H. Timmermans. 2005. Representing mental maps and cognitive learning in microsimulation models of activity-travel choice dynamics. Transportation 32: 321-340. http://dx.doi.org/ 10.1007/s11116-004-7964-1.

Badoe, D., and E. Miller. 2000. Transportation-land use interaction: Empirical findings in North America, and their implications for modeling. Transportation Research Part D 5(4): 235-263. http://dx.doi.org/10.1016/S1361-9209(99)00036-X.

Bhat, C., and R. Gossen. 2004. A mixed multinomial logit model analysis of weekend recreational episode type choice. Transportation Research Part B 38: 767-787. http://dx.doi.org/10.1016/j.trb.2003.10.003.

Brownson, R., C. Hoehner, K. Day, A. Forsyth, and J. Sallis. 2009. Measuring the built environment for physical activity: State of the science. American Journal of Preventive Medicine 36(4): S99-123. e12. http://dx.doi.org/10.1016/j.amepre.2009.01.005.

Burns, L. 1979. Transportation, Temporal, and Spatial Components of Accessibility. Lexington, MA: D.C. Heath and Company. 
Cervero, R. 1996. Mixed land-uses and commuting: Evidence from the American Housing Survey. Transportation Research Part A 30(5): 361-377. http://dx.doi.org/10.1016/0965-8564(95)00033-X.

Cervero, R., and K. Kockelman. 1997. Travel demand and the 3Ds: Density, diversity, and design. Transportation Research Part D 2(3): 199-219.: http://dx.doi.org/10.1016/S1361-9209(97)00009-6.

Chen, Y., S. Ravulaparthy, K. Deutsch, P. Dalal, S. Y. Yoon, T. Lei, K. Goulias, R. Pendyala, C. Bhat, and H-H. Hu. 2011. Development of indicators of opportunity-based accessibility. Transportation Research Record 2255: 58-68. http://dx.doi.org/10.3141/2255-07.

Chiu, Y-C., J. Bottom, M. Mahut, A. Paz, R. Balakrishna, T. Waller, and J. Hicks. 2011. Dynamic traffic assignment: A primer. Transportation Research Circular E-C153. Washington, DC: Transportation Research Board of the National Academies. http://onlinepubs.trb.org/onlinepubs/circulars/ec153.pdf.

Christian, H., F. Bull, N. Middleton, M. Knuiman, M. Divitni, P. Hooper, A. Amarasinghe, and B. Giles-Corti. 2011. How important is the land-use mix measure in understanding walking behavior? Results from the RESIDE study. International Journal of Behavioral Nutrition and Physical Activity 8: 55-67. http://dx.doi.org/10.1186/1479-5868-8-55.

Clark, A., and D. Scott. 2014. Understanding the impact of the modifiable areal unit problem on the relationship between active travel and the built environment. Urban Studies 51(2): 284-299. http://dx.doi.org/10.1177/0042098013489742.

Clifton, K., R. Ewing, G-J. Knaap, and Y. Song. 2008. Quantitative analysis of urban form: A multidisciplinary review. Journal of Urbanism: International Research on Placemaking and Urban Sustainability 1(1): 17-45. http://dx.doi.org/10.1080/17549170801903496.

Delafontaine, M., T. Neutens, T. Schwanen, and N. Van de Weghe. 2011. The impact of opening hours on the equity of individual space-time accessibility. Computers, Environment, and Urban Systems 35: 276-288. http://dx.doi.org/10.1016/j.compenvurbsys.2011.02.005.

Downs, A. 2005. Smart growth: Why we discuss it more than we do it. Journal of the American Planning Association 71(4): 367-378. http://dx.doi.org/10.1080/01944360508976707.

Duncan, M., E. Winkler, T. Sugiyama, E. Cerin, L. duToit, E. Leslie, and N. Owen. 2010. Relationships of land-use mix with walking for transport: Do land uses and geographical scale matter? Journal of Urban Health: Bulletin of the New York Academy of Medicine 87(5): 782-795. http://dx.doi.org/10.1007/s11524-010-9488-7.

Ewing, R., and R. Cervero. 2010. Travel and the built environment: A meta-analysis. Journal of the American Planning Association 76(3): 265-294. http://dx.doi.org/10.1080/01944361003766766.

Fan, Y., and A. Khattak. 2008. Urban form, individual spatial footprints, and travel: Examination of space-use behavior. Transportation Research Record 2082: 98-106. http://dx.doi.org/10.3141/2082-12.

Forsyth, A., M. Hearst, J. M. Oakes, and K. Schmitz. 2008. Design and destination: Factors influencing walking and total physical activity. Urban Studies 45(9): 1973-1996. http://dx.doi.org/10.1177/0042098008093386.

Fotheringham, A., and D. Wong. 1991. The modifiable areal unit problem in multivariate statistical analyses. Environment and Planning A 23: 1025-1044. http://dx.doi.org/10.1068/a231025.

Frank, L., and G. Pivo. 1994. Impacts of mixed use and density on utilization of three modes of travel: Single-occupant vehicle, transit, and walking. Transportation Research Record 1466: 44-52. http://www.trb.org.

Frank, L., T. Schmid, J. Sallis, and J. Chapman. 2005. Linking objectively measured physical activity with objectively measured urban form: Findings from SMARTRAQ. American Journal of Preventive Medicine 28(2S2): 117-125. http://dx.doi.org/10.1016/j.amepre.2004.11.001. 
Frank, L., M. Bradley, S. Kavage, J. Chapman, and T. K. Lawton. 2008. Urban form, travel time, and cost relationships with tour complexity and mode choice. Transportation 35: 37-54. http://dx.doi.org/10.1007/s11116-007-9136-6.

Gauvin, L., E. Robitaille, M. Rive, L. McLaren, C. Dassa, and L. Potvin. 2007. Conceptualizing and operationalizing neighborhoods: The conundrum of identifying territorial units. Canadian Journal of Public Health 98(1): S18-S26. http://www.jstor.org/stable/41994835.

Gehrke, S. R., and K. J. Clifton. 2014. Operationalizing land use diversity at varying geographic scales and its connection to mode choice. Presented at the 93rd Annual Meeting of the Transportation Research Board, Washington, DC, January 12-16, 2014. http://www.trb.org.

Geurs, K., and B. van Wee. 2004. Accessibility evaluation of land-use and transport strategies: Review and research directions. Journal of Transport Geography 12: 127-140. http://dx.doi.org/10.1016/j.jtrangeo.2003.10.005.

Guo, J., and C. Bhat. 2007. Operationalizing the concept of neighborhood: Application to residential location choice analysis. Journal of Transport Geography 15: 31-45. http://dx.doi.org/10.1016/j.jtrangeo.2005.11.001.

Hagerstrand, T. 1970. What about people in regional science? Papers in Regional Science 24(1): 6-21. http://dx.doi.org/10.1111/j.1435-5597.1970.tb01464.x.

Handy, S., M. Boarnet, R. Ewing, and R. Killingsworth. 2002. How the built environment affects physical activity: View from urban planning. American Journal of Preventive Medicine 23(2S): 64-73. http://dx.doi.org/10.1016/S0749-3797(02)00475-0

Handy, S. 2005. Smart growth and the transportation-land use connection: What does the research tell us? International Regional Science Review 28(2): 146-167. http://dx.doi.org/10.1177/0160017604273626.

Hansen, W. 1959. How accessibility shapes land use. Journal of the American Institute of Planners 25(2): 73-76. http://dx.doi.org/10.1080/01944365908978307.

Hanson, S. 1980. The importance of the multi-purpose journey to work in urban travel behavior. Transportation 9: 229-248. http://dx.doi.org/10.1007/BF00153866.

Hess, P. M., A. Vernez Moudon, and M. Logsdon. 2001. Measuring land-use patterns for transportation research. Transportation Research Record 1780: 17-24. http://dx.doi.org/10.3141/1780-03.

Hong, J., Q. Shen, and L. Zhang. 2013. How do built-environment factors affect travel behavior? A spatial analysis at different geographic scales. Transportation 41: 419-440. http://dx.doi.org/10.1007/s11116-013-9462-9

Horton, F., and D. Reynolds. 1971. Effects of urban spatial structure on individual behavior. Economic Geography 47(1): 36-48. http://www.jstor.org/stable/143224.

Kockelman, K. 1997. Travel behavior as function of accessibility, land-use mixing, and land-use balance: Evidence from San Francisco Bay Area. Transportation Research Record 1607: 116-125. http://dx.doi.org/10.3141/1607-16.

Krizek, K. 2003a. Residential relocation and changes in urban travel: Does neighborhood-scale urban form matter? Journal of the American Planning Association 69(3): 265-281. http://dx.doi.org/10.1080/01944360308978019.

Krizek, K. 2003b. Operationalizing neighborhood accessibility for land use-travel behavior research and regional modeling. Journal of Planning Education and Research 22(3): 270-287. http://dx.doi.org/10.1177/0739456X02250315.

Kwan, M-P. 2013. Beyond space (as we knew it): Toward temporally integrated geographies of segregation, health, and accessibility. Annals of the Association of American Geographers 103(5): 1078-1086. http://dx.doi.org/10.1080/00045608.2013.792177. 
Kwan, M-P., and J. Weber. 2008. Scale and accessibility: Implications for the analysis of land use-travel interaction. Applied Geography 28: 110-123. http://dx.doi.org/10.1016/j.apgeog.2007.07.002.

Lenntorp, B. 1976. Paths in Space-Time Environments: A Time-Geographic Study of Movement Possibilities of Individuals. Lund, Sweden: The Royal University of Lund, Sweden.

Lynch, K. 1960. The Image of the City. Cambridge, MA: Massachusetts Institute of Technology.

Manaugh, K., and T. Kreider. 2013. What is mixed use? Presenting an interaction method for measuring land-use mix. The Journal of Transport and Land Use 6(1): 63-72. http://dx.doi.org/10.5198/jtlu.v6i1.291.

McNally, M., and A. Kulkarni. 1997. Assessment of influence of land use-transportation system on travel behavior. Transportation Research Record 1607: 105-115. http://dx.doi.org/10.3141/1607-15.

Metro. May 2011. State of the Centers: Investing in Our Communities. http://library.oregonmetro.gov /files /11-01-11_soc-_final_-_web.pdf.

Miller, H. 1999. Measuring space-time accessibility benefits within transportation networks: Basic theory and computational procedures. Geographical Analysis 31(1): 1-26. http://dx.doi.org/10.1111/j.1538-4632.1999.tb00408.x.

Miller, H. 2005. A measurement theory for time geography. Geographical Analysis 37: 17-45. http://dx.doi.org/10.1111/j.1538-4632.2005.00575.x.

Mitra, R., and R. Buliung. 2012. Built environment correlates of active school transportation: Neighborhood and the modifiable areal unit problem. Journal of Transport Geography 20: 51-61. http://dx.doi.org/10.1016/j.jtrangeo.2011.07.009.

Neutens, T., F. Witlox, N. Van de Weghe, and P. de Maeyer. 2007. Space-time opportunities for multiple agents: A constraint-based approach. International Journal of Geographical Information Science 21(10): 1061-1076. http://dx.doi.org/10.1080/13658810601169873.

Neutens, T., T. Schwanen, and F. Witlox. 2011. The prism of everyday life: Towards a new research agenda for time geography. Transport Reviews 31(1): 25-47. http://dx.doi.org/10.1080/01441647. 2010.484153.

Neutens, T., M. Delafontaine, D. Scott, and P. De Maeyer. 2012. A GIS-based method to identify spatiotemporal gaps in public service delivery. Applied Geography 32(2): 253-264. http://dx.doi.org/10.1016/j.apgeog.2011.05.006.

Oliver, L., N. Schuurman, and A. Hall. 2007. Comparing circular and network buffers to examine the influence of land use on walking for leisure and errands. International Journal of Health Geographics 6(1): 41. http://dx.doi.org/10.1186/1476-072X-6-41.

Reilly, M., and J. Landis. (2003). The influence of built-form and land use on mode choice: Evidence from the 1996 Bay Area travel survey (IURD WP 2002-4(1)). Berkeley, CA: University of California Transportation Center. http://www.uctc.net/papers/669.pdf.

Rodriguez, D., K. Evenson, A. Diez Roux, and S. Brines. 2009. Land use, residential density, and walking: The multi-ethnic study of Atherosclerosis. American Journal of Preventive Medicine 37(5): 397-404. http://dx.doi.org/10.1016/j.amepre.2009.07.008.

Saelens, B., J. Sallis, and L. Frank. 2003. Environmental correlates of walking and cycling: Findings from the transportation, urban design, and planning literature. Annals of Behavioral Medicine 25(2): 80-91. http://dx.doi.org/10.1207/S15324796ABM2502_03.

Song, Y., and D. Rodriguez. 2005. The measurement of the level of mixed land uses: A synthetic approach. Carolina Transportation Program White Paper Series, Chapel Hill, NC. http://planningandactivity.unc.edu/Mixed\%20land\%20uses\%20White\%20Paper.pdf.

Song, Y., L. Merlin, and D. Rodriguez. 2013. Comparing measures of urban land-use mix. Computers, Environment and Urban Systems 42: 1-13. http://dx.doi.org/10.1016/j.compenvurbsys.2013.08.001. 
Weber, J., and M-P. Kwan. 2002. Bringing time back in: A study on the influence of travel time variations and facility opening hours on individual accessibility. The Professional Geographer 54(2): 226-240. http://dx.doi.org/10.1111/0033-0124.00328.

Yoon, S. Y., and K. Goulias. 2010. Impact of time-space prism accessibility on time use behavior and its propagation through intra-household interaction. Transportation Letters: The International Journal of Transportation Research 2: 245-260. http://dx.doi.org/10.3328/TL.2010.02.04.245-260.

Yoon, S. Y., S. Ravulaparthy, and K. Goulias. 2014. Dynamic diurnal social taxonomy of urban environments using data from a geocoded time use activity-travel diary and point-based business establishment inventory. Transportation Research Part A 68: 3-17. http://dx.doi.org/10.1016/j.tra.2014.01.004.

Zhang, M., and N. Kukadia. 2005. Metrics of urban form and the modifiable areal unit problem. Transportation Research Record 1902: 71-79. http://dx.doi.org/10.3141/1902-09. 